\title{
Interdisciplinary Research Career Development: Building Interdisciplinary Research Careers in Women's Health Program Best Practices
}

\author{
Steven E. Domino, M.D., Ph.D.,, Joann Bodurtha, M.D., M.P.H., ${ }^{2}$ Joan D. Nagel, M.D., M.P.H., ${ }^{3}$ \\ and the BIRCWH Program Leadership ${ }^{4}$
}

\begin{abstract}
Background: The Office of Research on Women's Health (ORWH) and the National Institutes of Health (NIH) Institutes and Centers and the Agency for Health Care Research and Quality (AHRQ) have sponsored an interdisciplinary research career development program in five funding cycles since 2000 through a K12 mechanism titled "Building Interdisciplinary Research Careers in Women's Health (BIRCWH)." As of 2010, 407 scholars have been supported in interdisciplinary women's health research and a total of 63 BIRCWH program awards have been made to 41 institutions across the U.S.

Methods: In an effort to share practical approaches to interdisciplinary research training, currently funded BIRCWH sites were invited to submit 300-word bullet-point style summaries describing their best practices in interdisciplinary research training following a common format with an emphasis on practices that are innovative, can be reproduced in other places, and advance women's health research.

Results and Conclusions: Twenty-six program narratives provide unique perspectives along with common elements and themes in interdisciplinary research training best practices.
\end{abstract}

\section{Introduction}

$\mathbf{T}$ he Office of Research on Women's Health (ORWH) at the National Institutes of Health (NIH) challenged academic medical centers to develop training programs in interdisciplinary research targeted to Women's Health under the 1999 Request for Applications titled, "Building Interdisciplinary Research Careers in Women's Health (BIRCWH)." ${ }^{11}$ With support from NIH Institutes and Centers and the Agency for Health Care Research and Quality (AHRQ), the BIRCWH interdisciplinary research career development award (K12) provides support for junior faculty members recently completing clinical training or postdoctoral fellowships and commencing interdisciplinary basic, translational, clinical, or health services research relevant to women's health. A major goal of the BIRCWH is to support the transition to research independence for men and women who are conducting research that cuts across scientific and professional boundaries that will reduce fragmentation in women's health issues and lead to improved health and health outcomes for women.
The program is open to junior faculty from a variety of disciplines, specialties, and fields. Since 2000, a total of 63 BIRCWH programs have been awarded to 41 institutions, 29 programs are active, and as of 2010, 407 scholars have been supported in interdisciplinary women's health research. In an effort to share practical approaches to interdisciplinary research training, currently funded BIRCWH sites were invited to submit 300-word bullet-point style summaries describing their best practices in interdisciplinary research training following a common format with an emphasis on practices that are innovative, can be reproduced in other places, and advance women's health research. This article presents 26 narratives with common elements and themes that emerged. The BIRCWH Program Leadership is given in the Appendix.

\section{Common Themes in Interdisciplinary Research Training}

Best practices in research career development

The challenges of funding, growing scientific complexity, life-work balance, teaching and clinical commitments, and

\footnotetext{
${ }^{1}$ Department of Obstetrics and Gynecology, University of Michigan, Ann Arbor, Michigan.

${ }^{2}$ Departments of Human and Molecular Genetics, Pediatrics, Obstetrics-Gynecology, Epidemiology, and Community Health, Virginia Commonwealth University, Richmond, Virginia.

${ }^{3}$ Office of Research on Women's Health, National Institutes of Health, Bethesda, Maryland.

${ }^{4}$ Names and institutions in Appendix.
} 
many others impact current young investigators in team science. $^{2}$ BIRCWH programs indicate that mentoring teams, integration with Clinical and Translational Science Awards (CTSA) and other university-wide training in career development and research, inclusion in planning committees for training and visiting professorships, specific focus on bringing reports to submission, collaboration in a women's health community project, integration with other university women's health initiatives (e.g., Annual Research Day), and structured evaluations with benchmarks are strategies that make the BIRCWH program the model for K12 programs that provide junior faculty training and career development in an interdisciplinary environment at their institutions. ${ }^{3}$ Programs emphasize the transition to independence through their didactics, discussions, and mentoring. For example, Vanderbilt University fosters "manuscript sprint" meetings of four or five trainees across disciplines to participate in structured preparation of individual manuscripts over a limited time period. The structure provides accountability and culminates in final editing by a technical editor funded by the University.

\section{Foster interdisciplinary approaches and institutional change}

Successful interdisciplinary research requires some cultural changes in traditional departmental structures and reward systems but is clearly a priority of the NIH ORWH, as the interdisciplinary women's health research initiatives preceded the NIH Roadmap by several years. Interdisciplinary research has itself become a topic for research, 4,5 and BIRCWH programs are working to support scholars on the common path of successful career devel- opment based on interdisciplinary research in institutions that value this work. Since the BIRCWH program was developed, Interdisciplinary Women's Health Fellowships at a variety of institutions have developed across the country. Commonly mentioned strategies among BIRCWH programs include incorporating mentoring and interdisciplinary work in promotion and tenure guidelines, supporting women's health research initiatives that are interdisciplinary, and including interdisciplinary groupings in mentoring teams, research seminars, evaluation, and advisory committees. Several BIRCWH programs have been instrumental in enhancing institutional transformation, ranging from the Center for Women's Infectious Disease at Washington University that developed as a result of BIRCWH and Specialized Center of Research (SCOR) funding to several CTSAs that include women's health research as a strong emphasis.

\section{Advances in women's health}

The NIH ORWH has a rich history of supporting and transforming women's health research. ${ }^{6,7}$ Research topics of the BIRCWH scholars range across the life span from the single cell to the global population. The breadth and depth of the scholars' work is demonstrated by the summary statements herein as well as the BIRCWH annual meeting abstracts published in the Journal. BIRCWH program sites tailor research of scholars to take advantage of areas of expertise within each institution, typically focusing research in three or four areas of women's health.

\section{Best Practices Summaries}

\section{Boston University}

Innovations in Research Career Development

- Promoting Interdisciplinary Research

Two Scholars with their Mentors in four departments developed a joint research program interested in human papillomavirus (HPV) vaccine acceptance among minority populations. The BIRCWH program provided interdisciplinary mentoring, clearly demarcating unique specific aims for each Scholar while fostering collaboration.

- Models for Career Development

$\mathrm{BIRCWH}$ is the preferred model for other mentoring programs at the institution.

- Innovative in Research Regulatory Training

Assistant program director provides direct oversight and support to scholars for regulatory issues, including all Health Insurance Portability and Accountability Act (HIPPA) and Institutional Review Board (IRB) applications.

Foster Interdisciplinary Approaches and Institutional Change

Other training programs at BU have implemented many aspects

of the BIRCWH program:

- Surveillance protocol of nonresearch activities of trainees.

- Evaluation tools and protocols to assess the trainee advancement and mentoring effectiveness.

- Replicating the mentoring structure of BIRCWH for both research and educator junior faculty.

- The promotion criteria for both associate and full professor changed to explicitly state the expectation of mentoring for promotion, increasing the value of mentoring in the portfolio.

- Following funding of the BIRCWH program, The Boston University Women's Health Interdisciplinary Research Center (WHIRC) was founded in 2004 to promote women's health through research. Karen Freund, M.D., M.P.H., was named Director of WHIRC in January 2010. WHIRC received the largest individual donation ever committed to the School of Medicine to support the development of the Breast Cancer Research Center within WHIRC.

Advances in Women's Health

- Scholars have studied vulnerable populations, including HIV-positive women and aging and minority populations. Their research interests within vulnerable populations have spanned psychologic issues (depression, sexual trauma, and child protection), aging (dementia, falls, cardiac function, Parkinson's, end of life care), cancer (HPV risk, breast cancer risk perception), and metabolic issues (obesity, polycystic ovary syndrome [PCOS] and thyroid dysfunction). 


\section{Duke University/North Carolina Central University}

Innovation in Research Career Development

- Collaborative team of K12, KL2 leaders increases teamwork/communication; develops common career resources and programs.

- Junior Faculty Annual Research Day for Schools of Medicine, Nursing, Engineering, and Physical Therapy program.

- Interdisciplinary Faculty Development Committee sponsors manuscript and grant writing, laboratory management, promotion/tenure process, biostatistics, leadership, clinical research training, molecular biology, and communication courses.

- Encourage early career decisions toward women's health research by presentations to medical students on gender-based research.

- Bimonthly meetings of Scholars discuss work in progress, review and critique manuscripts and grants.

- Emphasize understanding and appreciation of scientific methods of wide variety of disciplines.

- Facilitate the use of Duke's Cores in basic, translational, and clinical research at NCCU.

Foster Interdisciplinary Approaches and Institutional Change

- Assisted in changing the criteria for promotion and tenure using a principle of contributions to team research. New criteria designed as a career development tool and as guide for chairs.

- Integrate BIRCWH into the Duke Translational Medicine Institute (CTSA initiated).

- Established annual BIRCWH Research Symposium to highlight uniqueness of all Women's Health Research.

- Promote diversity by the integration of NCCU Scholar into a research-intense university by appointing individual as Duke adjunct faculty. NCCU Scholar conducts research and uses resources, libraries, and career development programs at Duke. Duke faculty present at newly organized women's research symposium at NCCU.

Advances in Women's Health

- Scholars have advanced research in clinical trials (perinatal medicine/urogynecology,) H1N1 vaccination, thromboembolic disease, lupus in pregnancy, postpartum hemorrhage, oxytocin receptor regulation, breast cancer cell proliferation, gender differences in lung cancer outcomes and in elderly depressed individuals, new treatments for uterine fibroids, mechanisms of parathyroid disease, risk factors and susceptibility genes for pelvic floor prolapse, and the ethical medical treatment of women.

\section{Harvard University}

\section{Innovations in Research Career Development}

- Retain participation of Scholars in program as Senior Associate Scholars even after they have achieved successful independent funding, to participate in mentoring new Scholars.

- Provide an opportunity for our Scholars to give oral presentations at a Women's Health Workshop in order to showcase their successes and to provide them an opportunity to meet and network with additional junior and senior investigators with interests in women's health.

- Monthly meetings to provide fundamental education and training in women's health, gender biology, health disparities, translational research, genetics, and endocrinology.

- Guidance on grant and manuscript presentations, oral presentation skills, management and leadership of independent research programs, budgeting, and negotiation strategies.

- Identification and use of research resources available (with a particular emphasis on Harvard's NIH Clinical Translational Science Center).

- Visit to the Broad Institute, which brings together individuals from across MIT, Harvard, and the Harvard-affiliated hospitals, providing an opportunity for Scholars to learn about cutting edge genomic research and to think about how these approaches could be applied to their own work in women's health.

- Sessions dedicated to health disparities and information on how to incorporate this approach into their research.

- Create an awareness and recognition in the scholars that Women's Health and Gender Biology is a distinct field of study.

- Individual meetings of each Scholar with Drs. Goldstein and Kaiser to provide mentorship and guidance and to discuss the BIRCWH program, how it could best assist in their career development, and how it could enrich their understanding of and interest in Women's Health.

Foster Interdisciplinary Approaches and Institutional Change

- Broadened the awareness of our BIRCWH program at our institution to build interdisciplinary research careers in women's health.

- Held a Women's Health Mentoring and Networking Workshop, "Integrating Women's Health and Gender Biology into Studies of Health and Disease."

- Brought together early and senior investigators with research interests in women's health and gender biology through this workshop to provide a unique opportunity to share their work.

- Internal Advisory Committee participates in our Scholar recruitment, selection, and appointment efforts.

- Create an awareness and recognition of Women's Health and Gender Biology as a distinct field of study.

Advances in Women's Health

- Emphasis on translational bench to bedside research program.

- Program focuses on cardiovascular disorders, reproductive endocrine and neuroendocrine disorders, neuropsychiatric disorders, autoimmune disorders, and female cancers.

- Include investigators with an overarching focus on Genetics/Epigenetics throughout these areas to further emphasize our program theme. 


\section{Mayo Clinic}

\section{Innovations in Research Career Development}

- Leveraging existing didactic programs offered by the CTSA on grant and manuscript writing, statistics, clinical study design, epidemiology, mentorship, mock-study section participation.

- Participation in lunch career programs sponsored by the Office of Diversity.

- Including scholars on planning/organizational committees for seminars and continuing medical education (CME) programs.

Foster Interdisciplinary Approaches and Institutional Change

- Institutional-wide town hall meetings for clinicians/scientists interested in Women's Health. Input from these meetings was incorporated into a business plan for the Women's Health Research Center.

- Requiring mentoring committees for Scholars to be interdisciplinary.

- Incorporating topics in Women's Health and Sex/Gender Medicine into divisional/departmental grand rounds and seminars.

- Survey medical school/graduate school curriculum for topics of Women's Health and sex/gender-based science and medicine.

Advances in Women's Health

- Embedding topics of Women's Health into medical care, education, and research.

- Supported scholars are studying programs to reduce stress and improve the quality of life in caregivers of Alzheimer's patients, relationship between cardiovascular risk and dementia in menopausal women.

\section{Medical University of South Carolina}

Innovations in Research Career Development

- BIRCWH Scholars research addictions/mental health and aging/cognitive decline, with basic scientists and academic clinicians represented in both research areas.

- Scholars receive interactive mentoring by two faculty members representing clinical and preclinical discipline, providing expertise in research and career development.

- Comprehensive evaluation plan uses biannual formative and summative techniques as well as formal and informal approaches for reviewing and evaluating Scholar progress, mentorship, and program effectiveness.

- The entire BIRCWH K12 community attends regular meetings where Scholars discuss their research and crossdisciplinary collaborations are fostered.

Foster Interdisciplinary Approaches and Institutional Change

- BIRCWH participants work with MUSC Women Scholars Initiative to organize and attend seminars/workshops promoting information exchange and interdisciplinary interaction.

- Ongoing activities provide review/consultation in biostatistical analysis, research ethics, regulatory issues, human subject protection and privacy issues, and grantsmanship.

- Scholars present their data monthly to faculty and trainees of the SCOR on Sex and Gender Factors Affecting Women's Health to catalyze interdisciplinary collaboration.

- Scholars participate in exchanges with other interdisciplinary research groups at MUSC pertinent to BIRCWH Scholar's chosen research interests, fostering interdisciplinary perspectives and expanding networking opportunities for future collaborations.

\section{Advances in Women's Health}

- Scholars are advancing research in the following areas: preclinical investigation of stress, estrogen, and brain-derived neurotrophic factor interactions in the aging female brain; clinical investigation of gender differences in human cognitive decline; clinical investigation of gender differences in response to nicotine replacement therapy and denicotinized cigarette-facilitated extinction; preclinical investigation of ovarian hormonal effects on drug craving; clinical investigation of anti-N-methyl-D-aspartate receptor antibodies' association with neurocognitive dysfunction in pediatric patients with lupus and in the offspring of adult patients with lupus.

\section{Michigan State University}

Innovations in Research Career Development

- Written Mentor-Mentee agreements to establish expectations and goals.

- Scientific Seminar Series to expose Scholars to the broad array of Women's Health research, so they can learn more about how these individuals developed their careers, obtained funding, and maintain productivity. This also encourages peer mentoring as Scholars provide input into each other's projects.

- A monthly roundtable on career development. Topics include promotion requirements, research ethics, life balance, and development opportunities.

- Scholars must complete both human subjects training and animal use training regardless of their area of research.

- Scholars attend University programs on career development and research conduct. 
- As a group, Scholars choose a community service project in Women's Health to bring sharper focus to the ultimate goal of improving the health and lives of women.

Foster Interdisciplinary Approaches and Institutional Change

- Scholars, Mentors, and members of the Advisory Committee were intentionally selected for their interdisciplinary research topics and diverse backgrounds. All Scholars have two Mentors from our diverse pool and are encouraged to use other interdisciplinary mentors chosen for this purpose.

- Inventoried Women's Health research on campus to identify opportunities for interdisciplinary mentorship. The published inventory also increased awareness of Women's Health research at the higher levels of university administration.

- Presentations from leaders of key University programs that promote institutional change in research career development, including the two large National Science Foundation (NSF) funded programs, Advancing Diversity through the Alignment of Policies and Practices (ADAPP) and Center for Academic and Future Faculty Excellence (CAFFE).

Advances in Women's Health

- Reflecting the emphasis on interdisciplinary research, Scholars are advancing research in breast cancer in African American women, medical geography of access to care and outcome in the context of resource planning, the impact of visitation and custody arrangements on women when the male partner was an abuser, sexual health in aging women with a focus on provider-patient communication.

\section{Northwestern University}

Innovations in Research Career Development

- One-on-one manuscript writing, grant writing, and career development coaching by Beth Schachter of Scientist-toScientist Consulting.

- NU Clinical and Translational Sciences Institute (NUCATs) career development activities

- First Monday series develops skills for a successful academic career, including finding sources for funding, writing effective grants, and networking.

- Third Monday program provides a group mentoring experience that teaches the Scholars to efficiently critique their own work as well as that of others. Scholars receive critiques on their manuscripts and grant proposals.

- Inspired by Dr. Katherine Hartmann, Vanderbilt University BIRCWH, the Scholars organized and participated in three manuscript sprints. Each sprint lasted approximately 2 months, during which each scholar wrote a manuscript, received feedback from peers, and provided feedback for peers.

Foster Interdisciplinary Approaches and Institutional Change

- Scholars attend Institute for Women's Health Research monthly forum and have lunch with the speaker. Recent speakers of the forum included national experts on smoking and weight in women's health, colorectal cancer risk, scleroderma, cognitive function and obesity, and heart disease risk in women. BIRCWH Scholars Marla Clayman and Colleen Fitzgerald have presented their research in this forum.

- Meeting with Bill Lowe, Vice Dean for Academic Affairs, to discuss promotion process.

Advances in Women's Health

- Supported BIRCWH Scholars are advancing our understanding of diverse areas of interdisciplinary research, including (1) using pelvic musculoskeletal ultrasound to investigate the etiology of pregnancy-related pelvic pain, low back pain, and disability, (2) using clear and concise health information in the development of decision aids for BRCA testing, (3) obstructive sleep apnea in women, (4) genomic and histologic analysis of biomarkers of systemic sclerosis and response to various treatments, and (5) the role of short-chain fatty acids and their receptors in gestational diabetes.

\section{Oregon Health \& Science University}

Innovations in Research Career Development

- Scholars peer-to-peer grant and publication review. Scholars commit to each other to submit grants or publications in progress every 2 weeks for peer review. Primary and secondary reviewers assigned to each document. Facilitated discussion among scholars for feedback.

- Scholars present to grand rounds or research rounds of other departments for feedback on research.

- Program-specific funds for statistical and clinical regulatory assistance.

- Twice monthly, Design Studio meetings of diverse array of faculty to review grant proposals or implementation plans for recently funded grants.

- BIRCWH Scholars serve as study section reviewers for local Women's Health grant solicitations.

Foster Interdisciplinary Approaches and Institutional Change

- Monthly, all campus K12 or related career development meetings covering topics of mutual interest.

- Women's Health Conference open to public and all local institutions.

- BIRCWH is administered through Vice President for Research Office.

- Active BIRCWH Committee represent diverse interests (basic, clinical, translational, population), all dedicated to Women's Health. They invest heavily in contributing to career development plan and mentorship for individual applicants to promote interdisciplinary Women's Health research broadly, even among applicants who are not selected for BIRCWH. Committee also promoted interdisciplinary Women's Health research across institution.

- Focus on promotion and tenure processes and documentation that support, reward, and highlight team science. 
Advances in Women's Health

- Supported Scholars conduct research that spans Women's Health across the life cycle, including fetal programming of disease, adolescent and young adult oncofertility decision making, cardiovascular diseases in women, epigenetics of women's osteoporosis, age- and gender-specific differences in neuronal properties, mechanics of gender disparities in pain, disease, and treatment response.

\section{Pennsylvania State University}

Innovations in Research Career Development

- Monthly BIRCWH seminars incorporate career development topics and grantsmanship, coordinating with the Junior Faculty Development Program and including faculty with individual K awards. Workshopping of manuscripts and grant applications is included.

- Understanding gender and career development in academia. The annual Book Club discussed Mothers on the Fast Track by Mary Ann Mason and Eve Mason Ekman (Oxford, 2007); a BIRCWH seminar hosted a panel of women researchers discussing their career choices.

Foster Interdisciplinary Approaches and Institutional Change

- Developing our BIRCWH program across two campuses, the main campus and the College of Medicine. We require BIRCWH Scholars to have at least three faculty Mentors in at least two disciplines, with at least one Mentor on the other campus. This has fostered interactions across distinct disciplines and sharing tools from diverse fields.

- Facilitating recognition of interdisciplinary and collaborative research in promotion and tenure guidelines. The Penn State University strategic plan highlights the importance of such research, and the Colleges recognize the BIRCWH program in this context.

Advances in Women's Health

- Incorporating social scientists as BIRCWH Scholars. Applicants for Scholar positions included sociologists, demographers, psychologists, and health services researchers as well as clinicians. This mix has exposed all Scholars to the biopsychosocial framework and the importance of social context as a determinant of health. Both a clinician and a psychologist are studying intimate partner violence; a sociologist explored the social and biologic pathways by which obesity affects fertility; a clinician has incorporated psychologic concepts in cardiovascular disease prevention.

- Monthly BIRCWH Seminar Series and annual Book Club emphasize new perspectives in Women's Health research. We have discussed Gender and Health: The Effects of Constrained Choices and Social Policies by Chloe Bird and Patricia Rieker (Cambridge University Press, 2008) and the Institute of Medicine (IOM) report on Women's Health Research (2010).

\section{Tulane University}

Innovations in Research Career Development

- Provide guidance to Scholars on locating the best funding opportunities, specific to their particular needs.

- Scholars, assisted by Mentors, draft career development plans and timelines, based on self-efficacy survey results, to encourage strategic career planning.

- Collaborate with Xavier University, a less research-intensive, historically black university, to recruit Scholars and increase institutional research capacity.

- Highlight the importance of mentoring by incorporating documentation of mentoring experience as a requirement for promotion to full professor in the School of Public Health.

- Select diverse presenters at annual, schoolwide BIRCWH Women's Health Research Marathon (WHRM).

- Foster ongoing involvement of former Scholars as BIRCWH Associates, providing midlevel career mentorship to current Scholars.

- Provide technical support to Scholars in statistical analysis in study design, design of data collection instruments, and maintenance of study databases through the BIRCWH Women's Health Research Laboratory.

Foster Interdisciplinary Approaches and Institutional Change

- Cultivate cross-disciplinary research collaborations across the cardiovascular disease (CVD) spectrum among Scholars and Mentors of varying domains of expertise.

- WHRM represents 6 schools and 14 departments, thereby promoting cross-disciplinary research exposure.

- Invite multidisciplinary feedback on Scholar works in progress research presentations by fellow Scholars, Mentors, and Advisory Board members.

- Assist Scholars in identifying opportunities for research collaborations among themselves.

Advances in Women's Health

- Encourage institutional awareness of sex and gender differences through the establishment of the annual WHRM, thus increasing schoolwide research in Women's Health.

- With an umbrella focus on CVD and hypertension in a sex, gender, and life span perspective, supported Scholars have advanced Women's Health research by studying kidney transplant gender outcome disparities, genetic etiology of gender differences in salt sensitivity, role of pharmacists in community-based CVD prevention efforts, pregnancy and CVD, gender and social norms related to smoking and so on. 


\section{University of California, Davis}

Innovations in Research Career Development

- Creating mentoring teams that include both research and career Mentors.

- Networking with another regional BIRCWH program, including an annual symposium attended by Scholars and Mentors to foster collaboration.

- Using innovative technology to visualize research collaboration networks (including publications and grants); we document the evolving research networks of both Scholars and Mentors in terms of interdisciplinarity and sustained research focus on Women's Health. Our tools allow us to use the network data to track program and participant success over time.

Foster Interdisciplinary Approaches and Institutional Change

- Mentoring teams for Scholars include Mentors from a minimum of two different disciplines, which must be justified by Scholars and approved by the BIRCWH Principle Investigator (PI) and program directors.

- BIRCWH collaborates with our Faculty Development program and newly established Mentoring Academy to change the institutional environment and culture to provide incentives for engaging in team science and interdisciplinary collaboration by specifically rewarding those who are involved in interdisciplinary mentoring and research projects in the merits and promotions process.

- Through shared curriculum and activities, such as an annual research retreat and joint symposium with all institutional training programs, BIRCWH Scholars are exposed to research from a variety of disciplines, ranging from molecular to epidemiologic studies.

Advances in Women's Health

- Scholars have undertaken research, including the basic biology related to the influence of hormones and aging on bone modeling; clinical investigation of T cell activation in HIV-infected women compared to men; identifying gender, age, and racial differences in risk factors for osteoarthritis of the knee; population-based research on contraceptive sabotage among teens by abusive partners; the relation of violence to weight change and prediabetes; qualitative research on gender and racial/ethnic differences in depression; epigenetic studies on the role of maternal nutrition in the risk for neurodevelopmental disorders in their children.

\section{University of California, San Francisco}

\section{Innovations in Research Career Development}

Most effective practices:

- Transmentoring (inclusion of Mentors who are part of the Mentee's research group and Mentors who are outside of it).

- Individually tailored mentoring (format and quantity of mentoring is tailored to the Mentee's specific needs).

- Inclusion of female and minority Mentors into the mentoring team for female and minority Mentees.

- Use of mock study sections in advance of grant submissions to improve rate of success.

- Provision on information on career strategy, misconduct and avoiding it, job seeking, appraisal, coping with personal crises, and so on.

- Finding diverse role models and outlining their career strategies and trajectories.

- Training in how to address perceived weaknesses in grant applications and in academic review packets, including strategic use of letters of support.

Foster Interdisciplinary Approaches and Institutional Change

Approaches at our institutions

- This is very challenging.

- Advocating for the recognition of multiple key contributors to multidisciplinary research endeavors, establishing models of success that differ from the single PI in a silo model.

- Fostering interactions among diverse investigators.

- Promoting the concept that mixing diverse ideas leads to innovation.

- Identifying willing and open scientists and providing a format for novel interactions.

- Participation in campus leadership endeavors to advocate for women scientists.

Advances in Women's Health

How our program has furthered Women's Health:

- Thinking out of the box about what are the key issues in Women's Health.

- Recruiting investigators who are expert in target fields into BIRCWH and Women's Health research.

- Establishing mentoring teams that include these Women's Health novices with established Women's Health investigators.

- Creating key blogs and podcasts to make Women's Health prominent on campus and community.

\section{University of Cincinnati}

\section{Innovations in Research Career Development}

- Through our Center for Clinical and Translation Science and Training (CCTST, home to our CTSA), we have a series of resources for preparing K23 applications, including a library of funded K23s, a 10-12-month preparation timeline with milestones to be achieved along the way, and access to a medical writer. In addition, our BIRCWH applications 
are nearly identical in format and length as NIH K23 applications, so successful BIRCWH applicants are primed to submit K23s (or K08s).

- BIRCWH Scholars (and BIRCWH applicants) are invited to join our K Club, which comprises all career development awardees in our academic health center. The K Club's agenda is driven entirely by the K Club members and is only facilitated by the K Club directors.

- We put on lectures and workshops on effective (and ineffective) Mentor-Mentee relationships.

Foster Interdisciplinary Approaches and Institutional Change

- The College of Medicine's guidelines for promotion and tenure specifically recognize and reward interdisciplinary research.

- We use a team mentorship model, with teams comprising faculty from different disciplines.

- Our Internal Advisory Committee is multidis- ciplinary.

- We foster research (social) networking through the CCTST. All CCTST members-academic and community-are asked to list areas of interest and areas of expertise so that we can link people together.

- The CCTST conducts grand rounds presentations and workshops on interdisciplinary research, featuring nationally renowned experts in the field.

Advances in Women's Health

- Research foci of BIRCWH Scholars in Cincinnati have spanned the gamut of basic science, translational, and clinical topics. Among them are the association between depression and obesity among adolescent girls, the role of highdensity lipoprotein (HDL)-estradiol as a novel drug target for diabetes in women, alcohol use prevention in pregnancy, sexually transmitted infections in adolescents, HPV transmission and its relationship to cervical cancer, scleroderma in women, vitamin $\mathrm{D}_{3}$ receptor signaling and regulation of mammary gland development and breast cancer, and the role of brain and hypothalamic estrogen receptor alpha in regulating female energy homeostasis and in breast cancer.

\section{University of Colorado}

Innovations in Research Career Development

- Develop the institutional emphasis on Women's Health by introducing Women's Health Research Day, initiating a lecture series, participating in leading a series of talks and workshops on mentorship, providing training to allow Scholars to attain skills in leadership, and disseminating information about opportunities in Women's Health campuswide.

- Center for Women's Health Research provides additional grant opportunities and is a focal point for Women's Health research activities at the campus.

- Coordinate with institution's other training grant directors to take advantage of common career development resources, trainee recruitment, and collaboration.

- Encourage and help form strong mentorship teams so that the Scholars receive the optimal benefit from their BIRCWH tenure. Includes teaching Scholars how to negotiate for what they need to succeed in terms of resources, time for research, and other aspects critical to an academic career.

- Begin planning for postaward transition early on in the process of the BIRCWH Scholarship.

- Strong evaluation program assesses Scholars and Mentors.

Foster Interdisciplinary Approaches and Institutional Change

- BIRCWH Scholars bring together faculty Mentors from multiple scientific fields. In addition, all types of scientific endeavor are represented, ranging from basic to translational to clinical to epidemiology. Interdisciplinary collaborations result not only between Scholar and Mentor but also between Scholars and between Mentors, resulting in exciting new scientific relationships.

- BIRCWH Scholars are able to access statistical, grant writing, and manuscript preparation support mechanisms through BIRCWH and CTSA.

- The institution recognizes that women's health research cuts across many fields and appreciates and supports the removal of the silos in favor of interdisciplinary thought. Thus, the institution supports Women's Health research as an important effort.

Advances in Women's Health

- Supported BIRCWH scholars are advancing research in the areas of diabetes and the heart, fetal programming, puberty and metabolism, breast cancer in pregnancy, sex differences in the effects of obesity in CVD, diabetes and obesity in adolescents and aging.

\section{University of Illinois at Chicago}

Innovations in Research Career Development

- Monthly roundtable meetings of all Scholars and Mentors on research and career development topics, including leadership, mentoring, interdisciplinary issues in promotion and tenure, identifying Mentors and collaborators in other disciplines, grantsmanship, and mock reviews for grant applications.

- Scholars and Mentors take the lead in monthly meetings.

- Scholars are provided with career development funds through department-level and college-level cost-sharing agreements. 
- Clear program requirements for Scholars, Mentors, and program administration to ensure consistent levels of productivity and mentoring for all scholars.

- Each scholar has two or three mentors and a BIRCWH advisor (either PI or Program Director (PD)).

Foster Interdisciplinary Approaches and Institutional Change

- Six health colleges (Medicine, Nursing, Pharmacy, Dentistry, Public Health, and Applied Health Sciences) and two campuses (Chicago and Urbana-Champaign) represented among 10 Scholars and among 20 Mentors and 12 internal Advisory Board members.

- Exchange of ideas and approaches has resulted in novel collaborations between Scholars across departments and colleges (e.g., Pharmacy Practice, and Obstetrics \& Gynecology).

- As the result of participating in BIRCWH, some Mentors have begun studying sex differences in their own research.

- Other K Scholars and Women's Health research fellows (e.g., postdoctoral fellows supported by NIH diversity supplements) engage with BIRCWH Scholars through monthly meetings and other seminars.

- BIRCWH program is a key resource for mentorship and training programs university-wide, particularly UIC's CTSA.

Advances in Women's Health

- UIC BIRCWH Scholars study contraceptive decision making, hormonal regulation of hepatic drug-metabolizing enzymes, gender differences in cognitive vulnerabilities for risk behavior in adolescents, early transformative events in ovarian cancer, emerging reproductive and genetic technologies, sex differences in glaucoma, obesity in pregnancy, placental nutrient transfer and later reproductive health, gender role impact on health behaviors, and neurohormonal effects on women's mental health.

\section{University of Kansas}

Innovations in Research Career Development

- Connects junior scientists within our institution and across the country leading to meaningful, long-lasting collaborations.

- Monthly meetings allow opportunity to meet with visiting research experts and provide the support to build a foundation for successful research careers and sustainable NIH funding.

- Allows young investigators to work with expert Mentors and develop a career path with direction, collaboration, and feedback from investigators with diverse points of view.

- Former Scholars encouraged to attend monthly BIRCWH meetings, providing peer mentoring.

Foster Interdisciplinary Approaches and Institutional Change

- Interdisciplinary activities include the incorporation of ethics, social determinants of health and topics of diversity; multidisciplinary approaches to clinical research; and access to content matter experts presented at BIRCWH-sponsored lectures.

- Scholars and Mentors come from a variety of disciplines, departments, and schools, promoting creative thinking.

- Scholars establish connections with Scholars and faculty from other disciplines and training programs on campus. This network helps build a program of research to advance current knowledge and to translate effective research interventions to the clinical setting.

Advances in Women's Health

- Scholars learn about other topics in women's health outside of their area from other Scholars, BIRCWH mentors, and the annual meeting. They are better able to define their work more definitively as centered on the theme of Women's Health.

- BIRCWH program promotes research focused on the unique aspects of Women's Health. This focus has great potential to increase the quality of care provided to women while reducing costs, in terms of the personal and financial burden of conditions that affect women.

- Topics from BIRCWH-supported research target several major public health issues, including weight control and risk factors related to being overweight or obese; breast cancer and secondary prevention; and issues related to worldwide public health challenges, and should have a significant impact on Women's Health.

\section{University of Michigan}

Innovations in Research Career Development

- Build a wider women's health research community across disciplines, increasing contact and communication through regular monthly meetings, weekly email list, invited lectures.

- Coordinate with institution's other training grant directors to take advantage of common career development resources, trainee recruitment, and collaboration.

- Review Scholars' manuscripts and grants in a group setting to maximize writing education for all Scholars.

- Encourage and assist maintenance of a shared vision between Scholar and supervisors.

- Begin planning for postaward transition at the time of initial Scholar appointment.

Foster Interdisciplinary Approaches and Institutional Change

- Acknowledge the range of valid scientific approaches.

- Teach each other the language of individual disciplines to support communication.

- Provide framework for developing interdisciplinary teams: look for compatible personalities and interests and complementary abilities. 
- Encourage mindset and behaviors that facilitate interdisciplinary research:

- Value and respect collaborators' disciplines.

- Have confidence in and share what you know; admit what you do not know.

- Focusing on a good scientific question is more important than techniques or disciplinary boundaries.

- Work together toward a common goal.

- Avoid differing expectations, personality conflicts, and too individualized goals.

- Share credit and celebrate successes.

- Alternate who does the traveling, where to meet, who presents.

- With seniority, take on more high-risk-high-reward projects.

Advances in Women's Health

- Supported BIRCWH Scholars are advancing research in diverse areas, including HPV vaccination, gender differences in depression, racial health disparities, stillbirth, breast cancer treatment side effects, chronic pelvic pain, obesity and obstetric outcomes, pelvic floor prolapse and labor management, transplant outcomes, aging, reproductive stem cells, early pregnancy failure, aging, workplace civility, obesity in adolescent girls.

University of Minnesota

Innovations in Research Career Development

- Core curriculum with goals and competencies in Women's Health, research, dissemination, resource development and management, advocacy, interprofessional leadership, and academic role.

- Use of career development plans and Gantt charts for guiding research and scholarship productivity.

- Mentoring team workshop for Scholars and Mentors at launch of BIRCWH Scholar's award.

- Specialized training in health disparities research methods, using research to impact policy and speaking to the media.

- Powell Center for Women's Health provides additional grant opportunities and is a focal point for Women's Health research activities at the University.

- Strong interdisciplinary mentoring teams. Addition of a school Mentor to provide guidance regarding promotion and tenure requirements.

- Women's Health Research Journal Club with senior researchers.

Foster Interdisciplinary Approaches and Institutional Change

- Each Scholar has a minimum of two Mentors from different disciplines. Mentoring teams are required to meet twice a year.

- Interdisciplinary Advisory Committee representing all five Academic Health Science Schools and the College of Liberal Arts; committee members have diverse backgrounds from basic, clinical, and translational research.

- Participate in an Interdisciplinary Annual Women's Health Research Conference.

- Collaborate with other K12 training programs in offering weekly research seminars and mock grant reviews.

Advances in Women's Health

- Developed new research collaborations among Scholars, Mentors, interdisciplinary advisory committee members, and other senior researchers.

- Supported Scholars studying adolescent obesity, mental health of Latina adolescents, cervical cancer screening, biomarkers for bone loss, gender differences in pharmacogenomics, biomarkers for breast cancer, and disability prevention in older women.

\section{University of North Carolina at Chapel Hill}

Innovations in Research Career Development

- The BIRCWH Program at UNC-CH is administratively housed within the Education, Training and Career Development (ETCD) Core of the CTSA-funded North Carolina Translational and Clinical Sciences Institute. This allows BIRCWH Scholars to benefit from faculty, other Scholars with diverse interests and backgrounds, and curricula supported by the ETCD. Because a major goal of the CTSA is to train and support the next generation of biomedical researchers, this is mutually beneficial to both programs.

- Faculty: BIRCWH Scholars have access to faculty supported by the ETCD, who are expert in teaching core competencies essential for biomedical researchers and mentoring Scholars toward maximizing their research and scholarly productivity.

- Research resources: The ETCD supports two biostatisticians and an epidemiologist who together support institutional K Scholars to prepare research projects, grants, publications, and presentations. Through the Institute, Scholars also have access to pilot funding, regulatory assistance, and clinical facilities.

Foster Interdisciplinary Approaches and Institutional Change

- Network of Scholars: BIRCWH Scholars have frequent interactions with their colleagues from other UNC K programs through courses and seminars. This diverse group shares the goal of launching a career as an independently funded investigator. Scholars serve as collaborators and peer reviewers for the work of their colleagues. This not only helps to improve the product but also begins to teach the concepts of peer review. Ultimately, we are creating an environment and support system that will enhance Scholars' long-term research success. 
Advances in Women's Health

- Promotion of Women's Health research: In linking the BIRCWH program to the ETCD, we increase the awareness about issues related to Women's Health within our CTSA and with Scholars supported by K awards. This, in turn, stimulates the formation of collaborations and interdisciplinary teams that will benefit the BIRCWH Scholars and Women's Health research for many years to come.

\section{University of Pittsburgh}

Innovations in Research Career Development

- Brown Bag Conferences with Career Discussion.

- Participation in University Career Development Programs.

- Scholars meeting with Senior K12 Scholars and those who have recently completed these programs for pertinent (and timely) tips.

- Provided program-specific funds for statistical services to help support Scholars.

- Worked with CTSA to provide Mock Study Section reviews for grants to be submitted, with excellent success.

Foster Interdisciplinary Approaches and Institutional Change

- We have concentrated on recruiting individuals of diverse research backgrounds to guarantee a multidisciplinary environment for our Scholars.

- We tailor Mentor groups to guarantee this for each Scholar and, indeed, require that accepted Scholars have Mentors from at least two different disciplines.

- We have constructed an Internal Advisory Committee from diverse departments and research backgrounds (basic science, health services, clinical research) who meet with BIRCWH Scholars at least twice yearly to review their work and progress; this group serves as a resource for networking.

- Encouraged peer mentoring and collaborations in our diverse group of Scholars.

- Encouraged attendance and presentation at Magee-Womens Research Institute Work-in-Progress Seminar Series to broaden exposure to well-established interdisciplinary research projects within the University and outside through invited guest speakers.

Advances in Women's Health

- Encouraged Scholars to act as mentors for residents, fellows, and students.

- Supported Scholars' work in several areas relevant to Women's Health, including pelvic organ prolapse (biomechanical and psychologic), predictors of CVD in women, and midlife depression.

\section{University of Texas Medical Branch, Galveston}

Innovations in Research Career Development

- Conduct regular and often evaluations of Scholar progress as measured against the individual needs assessment.

- Provide experience in multidimensional writers' groups to maximize a broad range of input: peers and senior investigators/Mentors; peers and successful former Scholars; peers only.

- Provide one-to-one consult/critique sessions with professional academic/scientific writers.

- Provide statistical support through a resource laboratory.

- Center for Interdisciplinary Research in Women's Health (CIRWH) provides seed grants for pilot studies, offers seminars, holds poster sessions, and provides access to an expert on scientific writing.

Foster Interdisciplinary Approaches and Institutional Change

- CIRWH serves as a central forum, bringing senior and junior investigators together from all schools and many disciplines.

- CIRWH senior investigators also hold leadership positions in the CTSA or one of the other K12s on campus.

- CIRWH senior investigators comprise the Mentor pool for BIRCWH; thus, they may easily link BIRCWH Scholars with appropriate collaborators, available resources, and programs.

- CIRWH maintains a BIRCWH website promoting the visibility of the program and the accomplishments of the Scholars.

- CIRWH works with the CTSA to provide and promote a combined seminar program (Translational Research Scholars Program), providing young researchers, including BIRCWH Scholars, an interdisciplinary venue for presentation of their projects.

- BIRCWH Scholars, with offices across campus, come together regularly, creating a bidirectional effect on fostering interdisciplinary relationships, which in turn promotes institutional change.

Advances in Women's Health

- BIRCWH Scholars from medicine, nursing, and the health professions, representing training in aging, family medicine, obstetrics/gynecology, surgery, rehabilitation, psychology, sociology, epidemiology, and demography, have produced nearly 200 publications. These articles address the health needs of underrepresented, low-income women in the areas of breast cancer, cancer prevention, obesity, drug transport across the placenta, sleep quality/health outcomes, stroke outcomes, violence prevention, body image/weight control behaviors. 
University of Wisconsin, Madison

Innovations in Research Career Development

- BIRCWH Scholars are encouraged to practice presentations at monthly Professional Development Luncheons, to allow the Scholars to experience peer review and receive/provide constructive feedback.

- Collaborate with postdoctoral Scholars from other programs to share research tools and career development tips, during monthly Professional Development Luncheons.

- Engage Scholars specific training faculty in semiannual Mentor Meetings, designed to review career development plans and progress.

- Scholars give a formal presentation of their research at the annual Advisory Committee meeting, and evaluations are completed by the Advisory Committee members and training faculty. The Scholar meets with the Program Director to discuss the evaluation.

- Scholars should plan to write for a $\mathrm{K}$ or an $\mathrm{R}$ award, during years 2 and 3, using year 4 for rewriting and resubmitting as necessary.

Foster Interdisciplinary Approaches and Institutional Change

- Monthly luncheons with postdoctoral trainees and K awardees from Departments of Social Work, Psychology, Economics, for example, promote interdisciplinary collaboration

- Engage interdisciplinary Advisory Committee members and training faculty, consisting of physician scientists, perinatal researchers, sociologists, nurse scientists, nutritional scientists, epidemiologists, and economists.

- To promote interdisciplinary research and disciplinary cross-training, we provide two Mentors for each Scholar, balancing the biomedical/basic science and behavioral/demography and epidemiology approaches to address

Women's Health.

Advances in Women's Health

- Supported BIRCWH Scholars are advancing research in diverse areas, including treatment and prevention of musculoskeletal sports-related injuries sustained in childhood and adolescence, inflammatory bowel disease and the factors that predict disease activity in pregnancy, and investigating the molecular mechanisms and signaling pathways that are involved in oogenesis, folliculogenesis, fertilization, and early embryonic development in humans.

\section{Vanderbilt University}

Innovations in Research Career Development

- Pilot/feasibility funds rapidly available: $\leq \$ 2,000$ reviewed within 1 week, $\$ 2,000-\$ 10,000$ within 3 weeks; >\$10,000 reviewed with investigator presentation within 6 weeks. Awards to Scholars $>\$ 150,000$ in this cycle, in addition to BIRCWH award.

- Studios, coordinated by staff, convene experts to consult on study design, implementation, analysis, publication, and dissemination.

- Biostatistics Clinics available weekly.

- Mock grant review and library of funded K, R, and other awards provided.

- Timelines that project forward milestones, such as grant and manuscript submission (and resubmissions), are prepared by Scholars for a clear picture of the arc of their career development. Normative metrics are being provided.

Foster Interdisciplinary Approaches and Institutional Change

- Interdisciplinary Mentor panels meet formally twice yearly.

- Newman Society, a twice-monthly career development forum, includes all K awardees.

- Manuscript sprints convene teams of four or five trainees across disciplines to participate in structured preparation of manuscripts. Sprint teams provide accountability and culminate, for those who complete manuscripts (>95\%), access to a technical editor to suggest final edits.

- Connect Mentors together by providing timely "pushes" of information to circulate among mentors and their trainees, or to use in program leadership.

- Investigators with strong interdisciplinary funding records are encouraged at promotion to associate professor to strongly consider K24 application.

- Conversations feature books and media as the focal point for discussions across training programs and in multigeneration, cross-disciplinary conversations with researchers invited by senior leaders to participate.

Advances in Women's Health

- Scholars are familiar with the data and assist in outreach events for the Tennessee Women's Health Report Card.

- Scholars span the public health, psychosocial, clinical, translational, and basic sciences, working in areas that inform prevention, treatment, quality of care, and policy.

\section{Virginia Commonwealth University}

Innovations in Research Career Development

- Use broad advisory group to critique articles and grants in progress at monthly seminars.

- Encourage Scholars to select career development topics for discussion and take advantage of broader University resources. 
- Collaborate with other K Scholars in mentored monthly Discovery Dialogue series, hospital-based public seminars about research.

- Involve alumna to demonstrate the feasibility of the program goals and to exemplify possible paths to success.

- Use interdisciplinarity goal of CTSA/BIRCWH to impact promotion and tenure discussions.

Foster Interdisciplinary Approaches and Institutional Change

- K Scholars develop network across disciplines, that is, meshing the M.D. and Ph.D. perspectives with focus on translational projects.

- CTSA resources provide statistical, grant writing, and manuscript preparation support to ensure M.D.s are equipped with research tools and Ph.D.s access clinical resources and expertise.

- Educational seminars on laboratory management and navigational mentoring for orienting the Scholar aid in developing tools to fund interdisciplinary research.

Advances in Women's Health

- Model mentoring and development of students with focus on Women's Health.

- Increase focus on women's cancers with new models, ranging from very basic to preclinical.

- Supported Scholars have studied hormonal differences in pulmonary hypertension, glucose metabolism in PCOS, metabolic homeostasis in diabetes and obesity, the role of telomerase and adipose cells in breast cancer development, interactions between extracellular matrix signaling and genome stability in breast cancer, neuroendocrine tumor progression, the association of diabetes with mental health, lymphangiogenesis and sphingolipids in breast cancer progression.

\section{Washington University in St. Louis}

Innovations in Research Career Development

- A focused, mentored research experience for all Scholars, with additional mentoring input from a Scholar Career Development Committee as well as the Program Director.

- The BIRCWH Program Director chairs each of the Career Development Committees and encourages an atmosphere of guidance and counseling. Scholars present their progress with chalk talks to facilitate and focus on larger issues of scholarship, self-management, collaboration, and independence.

- The Scholars are encouraged and provided funds to host eminent professors who have made major contributions to research problems relevant to Women's Health. These interactions are meant to foster networking opportunities for the Scholars at early stages in their careers.

- The Scholars with Ph.D. training are offered an outpatient clinical experience focused on Women's Health.

Foster Interdisciplinary Approaches and Institutional Change

- The multiple disciplines represented on both the Advisory Committee and the Career Development Committees promote working relationships between clinical translational researchers and basic scientists. Many of the BIRCWHfostered interactions between department chairs and others in leadership positions formed the model for the current Institute for Clinical and Translation Science (ICTS) at Washington University, funded by the NIH's CTSA.

- The BIRCWH Scholars benefit from the ICTS, which offers curricula and training and research resources (mock study sections, library of successful grants, cores providing study design, and statistical analyses).

- The BIRCWH Program has integrated with the newly created Center for Women's Infectious Disease Research (CWIDR) at Washington University.

Advances in Women's Health

- Supported scholars are studying within 10 focus areas of Women's Health: autoimmune disease, cancer, CVD, complications of pregnancy, depression, diabetes/obesity/metabolism, epidemiology/health services research, genetics/pharmacogenomics, infectious diseases, and osteoporosis.

\section{Yale University}

Innovations in Research Career Development

- Career development model integrating research project mentoring with professional coaching.

- Focus on defining and working effectively in interdisciplinary team science.

- Tailored research project choices spanning a range of laboratory (animal, human) and community (treatment programs, medical clinics, school systems) settings focused on basic, translational, and clinical research.

- Funded and productive Mentors from multiple medical school departments and different disciplines.

- Immediate focus on manuscript writing from established datasets, project management of existing study, completion of pilot project for Scholar, and grant writing skills.

- Mentoring workshops for faculty and Scholars of all levels where Scholars are placed.

Foster Interdisciplinary Approaches and Institutional Change

- Use of a center (in our case, Women's Health Research at Yale, Yale's interdisciplinary research center on health and gender) in coordinating interdisciplinary research on sex and gender-specific differences in addictive behaviors.

- Collaboration with other interdisciplinary research centers and career development programs related to our content area.

- Monthly professional development brown bag lunches inviting faculty from other institutional or individual K awards in medical school and CTSA. 
- Theme-based structured workgroup experiences across projects and disciplines that promote team science.

- Secondary Mentor and project within another discipline.

- Mentoring programs and institutional review processes that overcome obstacles to career development in team science.

- Changes in promotion criteria that incorporate the value of collaborative research and team science.

Advances in Women's Health

- Established location within a center devoted to advancing research on Women's Health.

- Disciplines represented include psychiatry, epidemiology/public health, experimental and clinical psychology, reproductive medicine, endocrinology.

- Supported scholars will study, for example, perinatal addiction and gender differences in social network influences, stress response, and smoking; gender differences in smoking and treatment development.

\section{Summary}

Interdisciplinary research training presents opportunities and challenges. The first-hand experiences of 26 BIRCWH program narratives provide a window on contemporary career development training in women's health research. Common themes can be divided among three categories: scholar preparation, interdisciplinary mentor teams, and institutional support. Training in research ethics, idea generation, collaboration, grantsmanship, presentation, and publication skills are necessary foundations for all research training programs. Maximizing interactions with other institutional training centers to take advantage of unique opportunities is also emphasized.

The BIRCWH program serves as a model of how to conduct interdisciplinary, team-based research that cuts across disciplines, fields, and departments. Innovative approaches to junior faculty development are encouraged, along with development of new policies for promotion and tenure for junior faculty whose research does not fit within traditional boundaries. Over 400 scholars have participated in the BIRCWH program, and the majority have gone on to receive independent research grants from the NIH, research foundations, and industry, which has led to the development of interdisciplinary research groups across the country and, in some cases, to institutional change. It is hoped that this may provide inspiration to academic centers to develop research career development programs that incorporate an interdisciplinary perspective from basic science to clinical research to the bedside and back. National progress in women's health research is now interwoven with the interdisciplinary scholarship of the next generation of leaders emerging from the BIRCWH programs' collective and collaborative training strengths.

\section{Acknowledgments}

We thank our colleagues in all BIRCWH programs for their efforts on behalf of interdisciplinary research training in women's health and Dr. Vivian W. Pinn and colleagues of the NIH Office of Research on Women's Health.

\section{Disclosure Statement}

The authors have no conflicts of interest to report.

\section{References}

1. Building interdisciplinary research careers in women's health, RFA-OD-99-008, NIH guide, September 7, 1999. Available at grants2.nih.gov/grants/guide/rfa-files/RFA-OD-99-008.html

2. Stokols D, Hall KL, Taylor BK, Moser RP. The science of team science: Overview of the field and introduction to the supplement. Am J Prev Med 2008;2:S77-S89.

3. Domino SE, Smith YS, Johnson TRB. Opportunities and challenges of interdisciplinary research career development: Implementation of a women's health research training program. J Womens Health 2007;16:256-261.

4. Aboelela SW, Larson E, Bakken S, et al. Defining interdisciplinary research: Conclusions from a critical review of the literature. Health Serv Res 2007;42:329-346.

5. Bindler RC, Richardson B, Daratha K, Wordell D. Interdisciplinary health science research collaboration: Strengths, challenges, and case example. Appl Nurs Res 2010 [Epub ahead of print]

6. Pinn V. Sixth Annual Interdisciplinary Women's Health Research Symposium. J Womens Health 2009;18:1487-1488.

7. Pinn VW, Blehar MC. Interdisciplinary women's health research and career development. In: Rayburn WF, Schulkin J, eds. Changing landscape of academic women's health care in the United States. International Library of Ethics, Law and the New Medicine 48. New York: Springer, 2011:53.

Address correspondence to: Steven E. Domino, M.D., Ph.D. Department of Obstetrics and Gynecology L4100 Von Voigtlander Women's Hospital 1500 East Medical Center Drive University of Michigan Ann Arbor, MI 48109-5276

E-mail: sedomino@med.umich.edu 


\section{Appendix: Building Interdisciplinary Research Careers in Women's Health (BIRCH) Program Leadership}

Boston University: Karen M. Freund, M.D., M.P.H., Rebecca Silliman, M.D., Ph.D., Bonnie J. Sherman, Ph.D.; Duke University-North Carolina Central University: Phyllis C. Leppert, M.D., Ph.D., Friederike Jayes, D.V.M., Ph.D., Sandra White, Ph.D., Eugene Oddone, M.D., MHSc; Harvard University: Jill Goldstein, Ph.D., Ursula B. Kaiser, M.D.; Mayo Clinic: Virginia M. Miller, Ph.D., Rebecca S. Bahn, M.D., Walter A. Rocca, M.D., Lynne T. Shuster, M.D., Adil E. Bharucha, MBBS, M.D.; Medical University of South Carolina: Kathleen T. Brady, M.D., Ph.D., Jacqueline F. McGinty, Ph.D.; Michigan State University: Mary D. Nettleman, M.D., M.S.; Northwestern University: Margrit Urbanek, Ph.D., Teresa K Woodruff, Ph.D., Andrea Dunaif, M.D.; Oregon Health\& Science University: Jeanne-Marie Guise, M.D., M.P.H., Daniel Dorsa, Ph.D.; Pennsylvania State University: Carol S. Weisman, Ph.D., Kristen H. Kjerulff, Ph.D., Cynthia Chuang, M.D.; Tulane University: Adrienne B. Warren, M.P.H., Jeanette H. Magnus, M.D., Ph.D., Carolyn C. Johnson, Ph.D.; University of California, Davis: Claire Pomeroy, M.D., M.B.A., Ellen Gold, Ph.D., Nancy E. Lane, M.D., Julie Rainwater, Ph.D.; University of California, San Francisco:
Ruth M. Greenblatt, M.D.; University of Cincinnati: Joel Tsevat, M.D., M.P.H., Kenneth Clark, Ph.D.; University of Colorado: Judith G Regensteiner, Ph.D., Margaret Neville, Ph.D., Nanette Santoro, M.D.; University of Illinois at Chicago: Stacie E. Geller, Ph.D., Tonda L. Hughes, Ph.D., Pauline M. Maki, Ph.D., Abby Koch, M.A.; University of Kansas: Patricia A. Thomas M.D., Susan Carlson, Ph.D.; University of Michigan: Steven E. Domino M.D., Ph.D., Yolanda R. Smith, M.D., M.S., Timothy R.B. Johnson M.D.; University of Minnesota: Jean F. Wyman, Ph.D., Nancy Raymond, M.D.; University of North Carolina at Chapel Hill: Eugene P. Orringer, M.D., Morris Weinberger, Ph.D., Susan Pusek, M.P.H., M.S.; University of Pittsburgh: James M. Roberts, M.D., Melissa McNeil, M.D., Michelle Broido, Ph.D.; University of Texas Medical Branch, Galveston: Abbey B. Berenson, M.D., M.S., Jean Freeman, Ph.D.; University of Wisconsin, Madison: Gloria E Sarto, M.D., Ph.D.; Vanderbilt University: Katherine E Hartmann, M.D., Ph.D., Nancy J. Brown, M.D.; Virginia Commonwealth University: Joann Bodurtha M.D., M.P.H., Aylin Rizki, Ph.D., Sarah Spiegel, Ph.D., Jerome Strauss, M.D., Ph.D.; Washington University in St. Louis: Thomas J. Baranski, M.D., Ph.D., Clay F. Semenkovich, M.D.; Yale University: Samuel Ball, Ph.D., Jacob K. Tebes, Ph.D., Carolyn M. Mazure, Ph.D. 
